\title{
The Role of Cardiotonic Steroids in the Pathogenesis of Cardiomyopathy in Chronic Kidney Disease
}

\author{
Davor Pavlovic \\ Cardiovascular Division, King's College London, Rayne Institute, St. Thomas' Hospital, London, UK
}

\section{Key Words}

Cardiotonic steroids - Chronic kidney disease - End-stage renal disease - Sodium potassium pump - Ouabain . Marinobufagenin · Bufalin · Telocinobufagin · Digoxin

\begin{abstract}
Cardiotonic steroids (CTS) are a new class of hormones that circulate in the blood and are divided into two distinct groups, cardenolides, such as ouabain and digoxin, and bufadienolides, such as marinobufagenin, telocinobufagin and bufalin. They have the ability to bind and inhibit the ubiquitous transport enzyme sodium potassium pump, thus regulating intracellular $\mathrm{Na}^{+}$concentration in every living cell. Although digoxin has been prescribed to heart failure patients for at least 200 years, the realization that CTS are endogenously produced has intensified research into their physiological and pathophysiological roles. Over the last two decades, substantial evidence has accumulated demonstrating the effects of endogenously synthesised CTS on the kidneys, vasculature and the heart. In this review, the current state of art and the controversies surrounding the manner in which CTS mediate their pathophysiological effects are discussed. Several potential therapeutic strategies have emerged as a result of our increased understanding of the role CTS play in health and disease.
\end{abstract}

(c) 2014 S. Karger AG, Basel

\section{KARGER}

(c) 2014 S. Karger AG, Basel

$1660-2110 / 14 / 1282-0011 \$ 39.50 / 0$

E-Mail karger@karger.com

www.karger.com/nec

\section{Introduction}

There is a complex relationship between the kidneys and the heart, with the activity of kidneys strongly influencing the activity of the heart and vice versa. In particular, it has been evident for many years that patients with chronic kidney disease (CKD) and end-stage renal disease (ESRD) are at an increased risk of developing cardiovascular disease. The data from the HOPE trial demonstrate that mild CKD is associated with a $40 \%$ increase in the risk of major adverse cardiovascular events [1]. Furthermore, approximately $50 \%$ of ESRD patients die prematurely of cardiovascular causes [2,3], and this percentage is not falling [2]. There is convincing clinical evidence that renal failure results in cardiomyopathy (the 'uraemic cardiomyopathy') often characterised by left ventricular hypertrophy, reduced ejection fraction, myocardial fibrosis and arrhythmias $[2,3]$. In addition, hypertension, coronary artery stenosis, diabetes and microvascular diseases presumably all contribute to the high risk of cardiovascular events observed in CKD/ESRD patients. Over the last 20 years, a number of studies in animals and humans have shown that, during CKD/ESRD, endogenous circulating cardiotonic steroid (CTS) concentrations are increased. All CTS bind and inhibit the activity of the sodium potassium pump (NKA) whose function is to maintain resting

Dr. Davor Pavlovic

Cardiac Physiology, Rayne Institute, St. Thomas' Hospital London SE1 7EH (UK)

E-Mail davor.pavlovic@ kcl.ac.uk 
membrane potential by establishing $\mathrm{Na}^{+}$and $\mathrm{K}^{+}$gradients across the plasma membrane. In this review article, the role that endogenous CTS play in the development of cardiovascular disease during CKD/ESRD is discussed.

\section{Structure and Function of the NKA}

Our understanding of the structure-function relationship of the NKA has greatly expanded with the discovery [4] and refinement [5-7] of NKA crystal structures. The NKA is composed of 2 subunits, $\alpha$ and $\beta$, and an accessory FXYD protein $[8,9]$. The minimum functional unit is made up of a $\alpha$ - and $\beta$-subunit macromolecular complex with $4 \alpha-\left(\alpha_{1}, \alpha_{2}, \alpha_{3}\right.$ and $\left.\alpha_{4}\right)$ and $3 \beta$-isoforms $\left(\beta_{1}, \beta_{2}\right.$ and $\left.\beta_{3}\right)[10,11]$. The $\alpha$-subunit, with 10 transmembrane segments, contains the binding sites for $\mathrm{Na}^{+}, \mathrm{K}^{+}$, ATP and CTS. The catalytic function of the NKA for transport of $\mathrm{Na}^{+}$and $\mathrm{K}^{+}$relies on the $\alpha$-subunit, whereas the association with the $\beta$-subunit is required for the complex to move through the secretory pathway to the plasma membrane $[12,13]$. Each of the $\alpha$ - and $\beta$-isoforms is encoded by its own gene and can potentially form 12 different NKA isozymes with distinct transport and pharmacological properties [14]. In the heart and kidneys the NKA $\alpha_{1^{-}}$ isoform is the dominant, ubiquitous isoform, regulating bulk $\mathrm{Na}^{+}$whereas $\alpha_{2}$ plays a more prominent role in smooth muscle contraction and to some extent contributes to inotropy in the heart (see Pavlovic et al. [9], fig. 1). NKA uses the free energy of hydrolysis of ATP to exchange 3 intracellular $\mathrm{Na}^{+}$ions for 2 extracellular $\mathrm{K}^{+}$ions, thus setting the electrochemical gradient for both $\mathrm{Na}^{+}$and $\mathrm{K}^{+}$ across the cell membrane. The NKA is therefore vital for maintaining the resting potential and $\mathrm{Na}^{+}$and $\mathrm{K}^{+}$gradients in almost every eukaryotic cell. These gradients ensure basic cellular homeostasis such as regulation of cell volume, essential ionic and amino acid transport processes. In excitable cells NKA activity restores the $\mathrm{Na}^{+}$and $\mathrm{K}^{+}$ gradients following depolarisation and in the kidney its activity provides the driving force for $\mathrm{Na}^{+}$reabsorption essential to control extracellular volume and blood pressure. Among the many $\mathrm{Na}^{+}$-dependent transmembrane transport processes in muscle cells, the activity of the NKA drives the $\mathrm{Na}^{+} / \mathrm{Ca}^{2+}$ exchanger (NCX) and thus regulates the concentration of $\mathrm{Ca}^{2+}$ in both the cytosol and the sarcoplasmic reticulum. An increase in $\mathrm{Na}^{+}$would limit 'forward mode' $\mathrm{Na}^{+} / \mathrm{Ca}^{2+}$ exchange $\left(\mathrm{Na}^{+}\right.$in, $\mathrm{Ca}^{2+}$ out $)$ and possibly even favour more $\mathrm{Ca}^{2+}$ influx and less $\mathrm{Ca}^{2+}$ efflux, resulting in a larger $\mathrm{Ca}^{2+}$ transient and therefore increased contractility [15]. This is the accepted mechanism of ac- tion for the inotropic effect of herbal remedies such as extract from foxglove (Digitalis purpurea), used to increase cardiac output in patients with congestive heart failure. The British physician William Withering first described these effects in his 1785 publication An Account of the Foxglove and Some of Its Medical Uses: With Practical Remarks on Dropsy and Other Diseases. Some 100 years later, Oswald Schmiedeberg isolated and identified the compound responsible for the inotropic effects of foxglove as digitoxin, a member of the CTS family.

\section{Cardiotonic Steroids}

Nanomolar concentrations of CTS, such as ouabain, digoxin, marinobufagenin, bufalin and telocinobufagin, are detected in serum of experimental animals and humans [16-28]. CTS can be divided into two structurally distinct groups, cardenolides and bufadienolides. Cardenolides, such as ouabain and digoxin, have a 5-membered unsaturated lactone ring attached to the steroid nucleus at position 17 , whereas the bufadienolides, such as marinobufagenin and telocinobufagin, have a doubly unsaturated 6-membered lactone ring (fig. 1). All cardenolides have a hydroxyl at position 14, whereas some bufadienolides have a $14-15$ epoxide. The steroid nucleus is sometimes glycosylated in position 3 . The steroid substitutions of some of the most commonly isolated CTS are summarised in figure 1.

\section{Cardenolides}

There is substantial evidence that endogenous ouabain is present in the circulation. Hamlyn et al. [21] were the first to identify a substance indistinguishable from ouabain in human serum. Subsequently, endogenous ouabain was detected in the blood of patients with essential hypertension [27, 29], congestive heart failure [30] and end-stage renal failure [31]. Some evidence exists for the presence of digoxin in human urine [32] and of digitoxose sugars in mammals $[33,34]$; however, this requires further characterisation.

\section{Bufadienolides}

Marinobufagenin was originally discovered in amphibians and subsequently isolated and identified in the urine of patients with myocardial infarction [16] and the serum of patients with terminal renal failure [25]. Structurally related telocinobufagin, the reduced form of marinobufagenin, was identified, by high-resolution mass spectrometry and nuclear magnetic resonance, as a con-
Pavlovic 
Fig. 1. Steroid structure of cardenolide and bufadienolide NKA inhibitors. Cardenolides have a 5-membered lactone ring, whereas the bufadienolides have a 6-membered lactone ring. Substitutions on various positions of the general steroid structure of cardenolide and bufadienolide NKA inhibitors are shown.
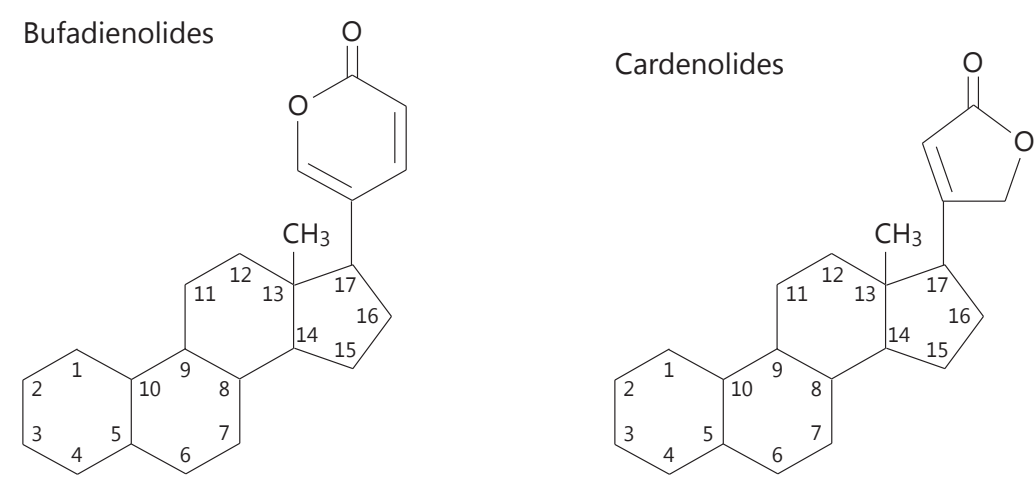

\begin{tabular}{|c|c|c|c|c|c|c|c|c|}
\hline & 1 & 3 & 5 & 10 & 11 & 12 & 14 & 16 \\
\hline \multicolumn{9}{|l|}{ Cardenolides } \\
\hline Digoxin & & $(\mathrm{Dig})_{3}$ & & & & $\mathrm{OH}$ & $\mathrm{OH}$ & \\
\hline Digitoxin & & $(\mathrm{Dig})_{3}$ & & & & & $\mathrm{OH}$ & \\
\hline Ouabain & $\mathrm{OH}$ & Rhamnose & $\mathrm{OH}$ & $\mathrm{CH}_{2} \mathrm{OH}$ & $\mathrm{OH}$ & & $\mathrm{OH}$ & \\
\hline \multicolumn{9}{|l|}{ Bufadienolides } \\
\hline Bufalin & & $\mathrm{OH}$ & & $\mathrm{CH}_{3}$ & & & $\mathrm{OH}$ & \\
\hline Proscillardin & & Rhamnose & & $\mathrm{CH}_{3}$ & & & $\mathrm{OH}$ & \\
\hline Marinobufagenin & & $\mathrm{OH}$ & $\mathrm{OH}$ & $\mathrm{CH}_{3}$ & & & $14-\mathrm{O}-15$ & \\
\hline Telocinobufagin & & $\mathrm{OH}$ & $\mathrm{OH}$ & $\mathrm{CH}_{3}$ & & & $\mathrm{OH}$ & \\
\hline
\end{tabular}

stituent of human serum in patients with terminal renal failure [25], at a higher concentration than that of marinobufagenin. It is likely that other bufadienolides may also be present in the circulation. Indeed there are reports of proscillaridin A- [35] and bufalin-like [36] immunoreactive substances detected in human serum.

\section{Biosynthesis of CTS}

Evidence is accumulating that most CTS are synthesised from cholesterol in the adrenal glands [37, 38] and possibly hypothalamus [39] but the biosynthetic pathways for cardenolides and bufadienolides seem to differ. The trigger for biosynthesis initiation is complex, with serum concentrations of ouabain and marinobufagenin increasing in response to volume expansion [40], salt accumulation in the brain, adrenocorticotropic hormone, angiotensin II, vasopressin and phenylephrine [37, 41].

\section{CTS Receptor Function: Ion Transport versus Signalling Pathway}

The classic model explaining the effects of CTS are based on the observations that enzymatic and transport functions of the NKA are reduced, thereby raising intra- cellular $\mathrm{Na}^{+}$and $\mathrm{Ca}^{2+}$ (via NCX). The effects of high $\mathrm{Ca}^{2+}$ on contractility [42] and induction of hypertrophic signalling cascades in the heart are well known [43]. However, when concentrations of CTS detected in serum of experimental animals and patients were shown to be in the range of $0.5-20 \mathrm{nM}$ [16-28], these were considered too low to modulate the activity of the NKA and thus were not expected to affect intracellular $\mathrm{Na}^{+}$and $\mathrm{Ca}^{2+}$ concentrations [44]. Therefore, in addition to its transport function, a hypothesis that the NKA also acts as a receptor for the CTS has been presented. Indeed, evidence is accumulating that the NKA also plays a signalling role [45], regulating early response genes associated with cell growth (see the review by Lie and Xie [46]). This model proposes that a fraction of NKA subunits are localised in the caveolae and are not involved in the transport of $\mathrm{Na}^{+}$and $\mathrm{K}^{+}$ions but instead act as receptors for CTS. These inactive' pumps are physically associated with other key signalling proteins such as epidermal growth factor (EGFR) and Src $[47,48]$, and binding of the CTS leads to activation of hypertrophic and fibrotic signalling cascades via NKA-Src-ERK [46]. The groups of Shapiro and Xie have shown that other signalling proteins are recruited, including phospholipase C, TRP proteins, phosphoinositide 3-kinase $\left(\mathrm{PI}_{3} \mathrm{~K}\right)$ and protein kinase $\mathrm{C}$ [44, 48-52], and 
Fig. 2. Schematic diagram of ionic versus signalling pathways for CTS effects. In the classic pathway (shown on the left), CTS binds and inhibits the NKA, which in turn is accompanied by changes in cytosolic $\left[\mathrm{Na}^{+}\right]$and $\left[\mathrm{K}^{+}\right]$. The increase in cytosolic $\left[\mathrm{Na}^{+}\right]$then reduces NCX activity and induces an increase in cytosolic $\left[\mathrm{Ca}^{2+}\right]$. High cytosolic $\left[\mathrm{Ca}^{2+}\right]$ mediates a muscle contraction or activates a variety of signalling pathways. The signalling pathway (shown on the right-hand side) occurs in the caveolar domain and involves the physical interaction with Src. When the CTS bind the NKA, Src gets activated inducing further activation of epidermal growth factor (EGFR) and phospholipase C (PLC). This leads to a cascade that involves generation of reactive oxygen species (ROS), activation of mitogen-activated protein kinase (ERK) through activation of its mitogenactivated protein kinase kinase (MEK), activation of $\mathrm{PI}_{3} \mathrm{~K}$, stimulation of endocytosis and activation of Akt as well as activation of protein kinase C. Adapted from Bagrov et al. [61].

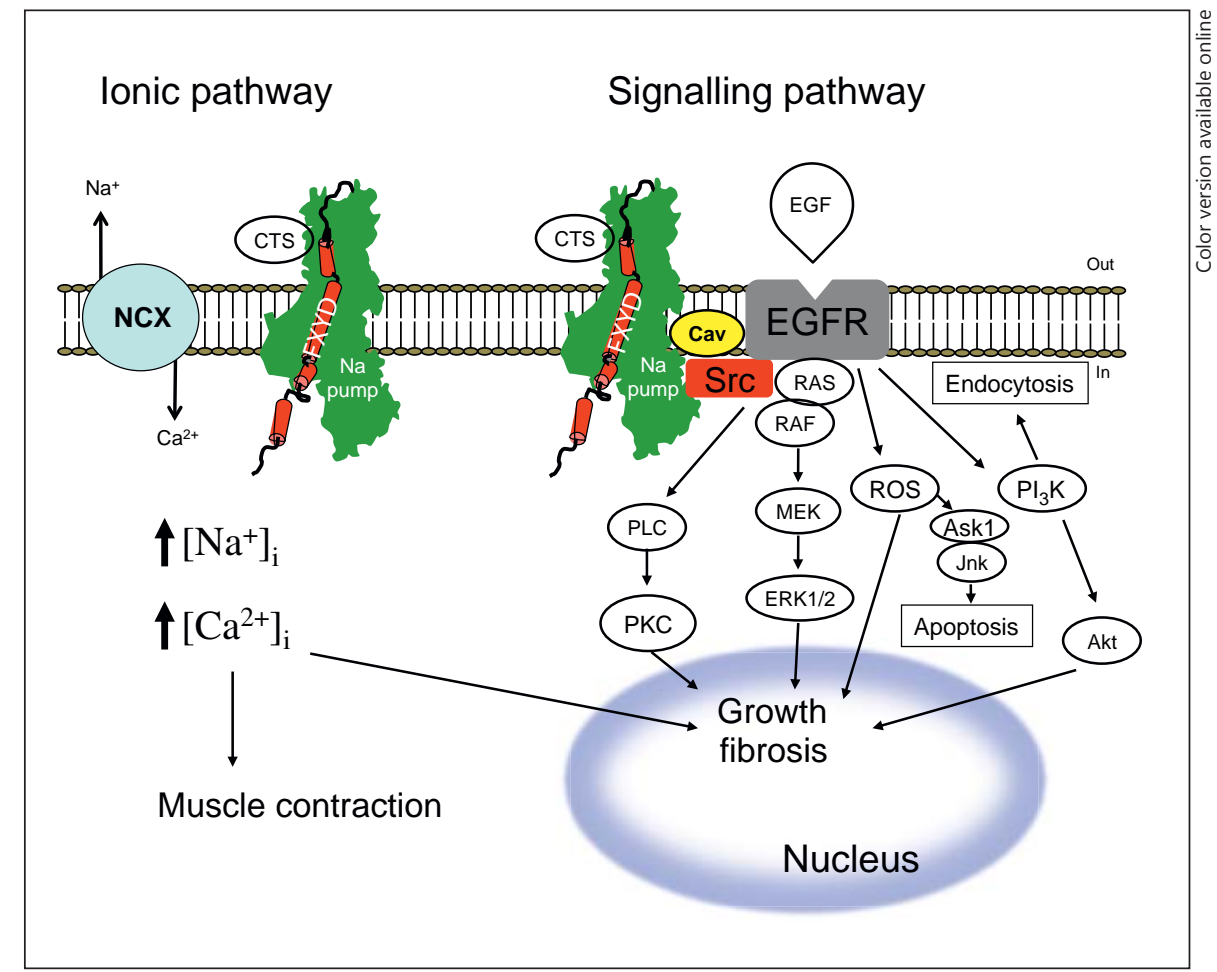

that the CTS induce the endocytosis of the CTS-NKASrc-EGFR complex [49-51]. Increased reactive oxygen species production that is $\mathrm{Ca}^{2+}$ sensitive has also been observed following CTS binding; however, the mechanisms by which CTS initiate reactive oxygen species production are unclear $[24,44,52]$. Whereas this alternative signalling pathway explains some of the effects of CTS, it does not account for the reported NKA inhibition that can be reversed by antidigitalis antibodies in patients with diabetes [53] or ESRD [28]. Furthermore, there is disagreement whether the activation of signalling cascades via CTS indeed occurs independently of NKA inhibition and the accompanying increases in intracellular $\mathrm{Na}^{+}$and $\mathrm{Ca}^{2+}$ $[54,55]$. Altamirano et al. [42] showed that acute inotropic effects of digoxin, acylstrophantidin and ouabain depend on the presence of intracellular $\mathrm{Na}^{+}$and a functional NCX. Reuter et al. [56] have also reported that the NCX is required for CTS to induce increased intracellular $\mathrm{Ca}^{2+}$. Furthermore, a recent study by Andrikopoulos et al. [57] reported that elevation of $\mathrm{Ca}^{2+}$ via ouabain-mediated NKA inhibition was sufficient to activate NKA-Src-ERK signalling cascades and lead to angiogenesis in human endothelial cells. Whether CTS induce hypertrophic growth in the heart via the ionic pathway or the signalling one remains to be resolved; however, the weight of evidence in support of both pathways makes it likely that they act in conjunction with each other. For details of the two pathways, please see figure 2 .

\section{CTS and Disease Pathogenesis}

\section{Hypertension}

Over the last 20 years, search for an endogenous ligand for the ouabain-binding site has intensified, and up to date 5 different CTS $[25,58-60]$ have been detected in circulation in humans and animals with varying NKA inhibitory properties (for a review, see Bagrov et al. [61]). Increases in endogenous CTS are particularly prominent in states of volume expansion and volume expansion-mediated hypertensive syndromes that are related to water and salt accumulation $[18,62,63]$. In healthy individuals, 3 days of salt loading led to a transient 13 -fold elevation in plasma ouabain and an increase in urine $\mathrm{Na}^{+}$excretion [40]. In another study of normotensive human subjects, 6 days of high salt intake resulted in a similar transient increase in plasma ouabain but a sustained increase in marinobufagenin that was directly correlated with an increase in urinary $\mathrm{Na}^{+}$excretion [64]. The hypothesis that CTS play a role in volume and blood pressure control is 
Fig. 3. Graphical representation of the proposed biosynthesis and function of endogenous CTS. Synthesis of endogenous CTS occurs in the adrenal cortex from cholesterol and is proposed to be under the control of adrenocorticotropic hormone $(\mathrm{ACTH})$ and angiotensin II. These are produced in response to a high salt load and the resultant ouabain synthesis in the hypothalamus. Acute effects of endogenous CTS are mediated via inhibition of the NKA and lead to increased cardiac output, $\mathrm{Na}^{+}$excretion and vasoconstriction (NKA isoform specific effects in each tissue are shown in red). Chronic exposure to CTS leads to adaptational remodelling changes of the affected tissue, possibly resulting in hypertrophy, fibrosis, hypertension and arrhythmogenesis. MBG = Marinobufagenin. Adapted from Schoner and Scheiner-Bobis [105].

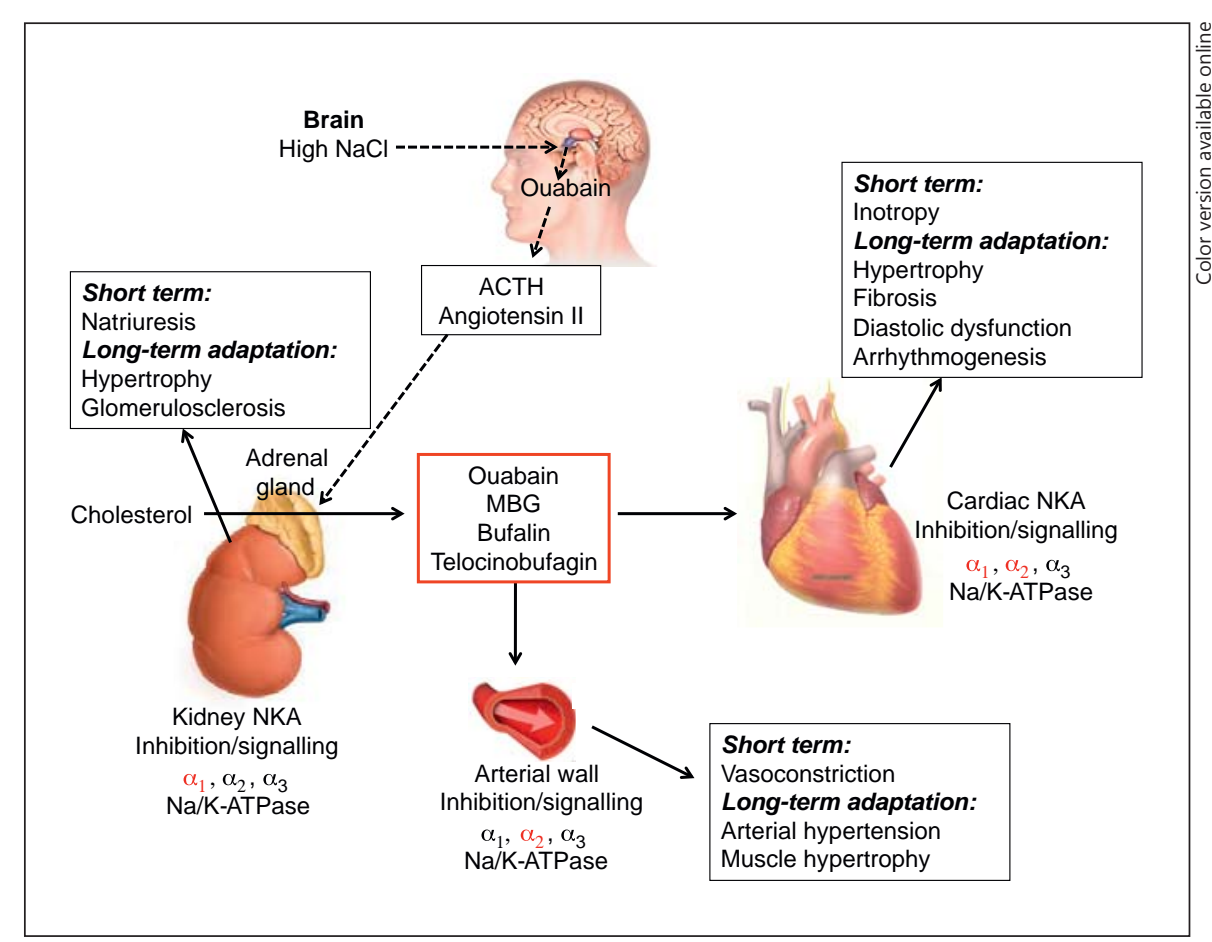

also supported by the facts that: (1) infusion of ouabain or marinobufagenin, at concentrations comparable with in vivo plasma levels, leads to an increase in blood pressure [24, 65-67]; (2) hypertension induced by either salt loading, ouabain infusion or pre-eclampsia was reduced by immunoneutralisation with anti-CTS antibodies [60, 68 ] or the CTS antagonists rostafuroxin [69] and resibufagenin [70]. While the effects of individual CTS on changes in blood pressure are complex and require further characterisation, taken together, these studies strongly implicate CTS in the pathogenesis of hypertension.

The mechanisms that govern hypertension development have not yet been fully elucidated; however, evidence is accumulating that in response to high salt intake, CTS are secreted by the brain [39] as well as the adrenal glands $[37,38]$ and that this leads to both central and peripheral blood pressure elevation and consequent salt excretion. Specifically, high salt intake elevates both plasma and cerebrospinal fluid $\mathrm{Na}^{+}[71,72]$, and this induces the secretion of CTS by the adrenals and the hypothalamus. Intracerebroventricular infusion of $\mathrm{Na}^{+}$-rich cerebrospinal fluid [73] or ouabain [71] increased sympathetic nerve activity, heart rate and blood pressure in rodents, and these effects were partially reversed by Digibind ${ }^{\circledR}$. There is reasonable evidence that this signalling cascade in the brain includes aldosterone, epithelial $\mathrm{Na}^{+}$channels, en- dogenous ouabain, $\alpha_{2}$-sodium pumps and angiotensin II (for a review, see Blaustein et al. [74]). Whereas the effects of brain-derived endogenous ouabain require further characterisation, plasma ouabain produced by the adrenal glands can contribute to acute vasoconstriction and increased myocardial contractility via inhibition of the $a_{2}$-sodium pumps in the smooth and cardiac muscle. Furthermore, CTS-mediated activation of the NKA-SrcEGFR complex (as discussed above in CTS Receptor Function: Ion Transport versus Signalling Pathway) is likely to contribute to functional remodelling of the affected tissue leading to hypertrophy and hypertension (fig. 3). Although reduction in endogenous CTS via antiCTS antibodies lowered urine sodium excretion, no changes in blood pressure were observed in healthy animals [75], suggesting that this pathway is inactive in the absence of salt-loading, volume-expanding conditions. This makes it particularly attractive to therapeutic exploitation. Disappointingly, in a recent Ouabain and Adducin for Specific Intervention on Sodium in Hypertension (OASIS-HT) phase 2 dose-finding trial, rostafuroxin (ouabain antagonist) did not reduce blood pressure at any dose [76]. However, more encouraging data are observed in patients with pre-eclampsia. Pregnancy is associated with plasma volume expansion as a result of renal $\mathrm{Na}^{+}$and fluid retention, thus not surprisingly, levels of endogenous 
ouabain and marinobufagenin were increased 4 -fold and 8 -fold, respectively, in patients with severe pre-eclampsia [77]. In vivo immunoneutralisation of CTS was presented as an unusual but therapeutically attractive option for the treatment of pre-eclampsia. In particular, 51 severely preeclamptic patients were treated with Digibind or placebo for $48 \mathrm{~h}$ [78]. Digibind was well tolerated, and results showed a reduction in decline in renal function and significantly improved NKA inhibition. Another exciting multi-centre, double-blind, placebo-controlled efficacy study of Digibind in pre-eclampsia (DEEP) has recently been concluded [79]. In women with severe pre-eclampsia who were remote from term and who were positive for CTS, the use of Digibind was associated with improved maternal and neonatal outcome. A large multi-centre trial that would evaluate the benefits of Digibind in the treatment of women with severe pre-eclampsia who are remote from term and with positive CTS status is required in order to confirm the results of the DEEP trial.

\section{Natriuresis}

The basis of natriuresis due to CTS is thought to be dependent on the direct inhibition of the NKA $\alpha_{1}$-isoform in renal tubular cells [63]. There is some evidence that marinobufagenin is the dominant CTS as marinobufagenin antibodies given to salt-loaded rats lowered urinary excretion and increased NKA activity [80]. However, due to the similar chemical structures of CTS, antibodies raised against individual CTS tend to have poor specificity [81]. Indeed, administration of ouabain or marinobufagenin resulted in inhibition and internalisation of the NKA by endocytosis in LLCPK1 cells, a model of proximal tubule cells, but no depletion was observed in MDCK cells, a cell line resembling distal tubular cells [51]. Ouabain was reported to stimulate a clathrin-dependent endocytosis pathway that translocates the NKA to intracellular compartments. This translocation required $\mathrm{PI}_{3} \mathrm{Kac}$ tivation, the plasmalemmal pump to be in the context of caveola, and signalling through the Src-EGFR pathway [50]. It is therefore suggested that salt-loading leads to increases in ouabain and marinobufagenin in the proximal tubules, both of which act to decrease $\mathrm{Na}^{+}$reabsorption through NKA inhibition and/or activation of a signalling mechanism mediated by NKA-Src-EGFR cascades. This decrease in renal $\mathrm{Na}^{+}$reabsorption is expected to lead to an increase in urinary $\mathrm{Na}^{+}$excretion and thus eventually to abrogation of hypertension. Indeed, 3 days of salt-loading in healthy individuals did not result in a change in blood pressure [40] suggesting that acute saltloading in a healthy individual has no pathological con- sequences. However, it is clear that during chronic saltloading or chronic CTS infusion, hypertension persists. It is likely that this is mediated via a combination of chronic elevation of brain $\mathrm{Na}^{+}$, leading to increased sympathetic nerve activity, and the direct effects of endogenous CTS on the smooth and cardiac muscle, potentially resulting in increased cardiac output, increased total peripheral resistance and thus elevation in blood pressure (as discussed in the previous section). Furthermore, adaptational changes induced via activation of the NKA-Src-EGFR complex may also participate in the arterial remodelling that is often associated with established hypertension [82].

\section{Renal Failure and Uraemic Cardiomyopathy}

Serum levels of ouabain, telocinobufagin and marinobufagenin are substantially elevated in patients with ESRD [25, 31]. Similar increases (albeit slightly lower than in ESRD) in ouabain and marinobufagenin were reported in animals with CKD $[24,83]$. In fact, plasma endogenous ouabain levels were shown to be powerful biomarkers of acute kidney injury and postoperative complications in cardiac surgery patients [84]. Plasma marinobufagenin levels were also increased in patients with renal artery stenosis, whereas reversal of renal ischaemia by stenting treatment reduced marinobufagenin concentrations, thus implying that renal artery stenosisinduced renal ischaemia may be a major cause of endogenous marinobufagenin synthesis [85]. There is clear evidence that chronic exposure to CTS can contribute to cardiovascular disease development. Sustained ouabain infusion in rats induces left ventricular hypertrophy [66], whereas the presence of left ventricular hypertrophy and reduction in ejection fraction are positively correlated with increased CTS concentrations in the serum of patients with essential hypertension [27, 29], congestive heart failure [30] and ESRD [31]. As discussed earlier, CTS inhibit NKA activity and as a consequence raise intracellular $\mathrm{Na}^{+}$and $\mathrm{Ca}^{2+}$ via the NCX [86]. A potentially lethal side effect of chronically raised $\mathrm{Ca}^{2+}$ is $\mathrm{Ca}^{2+}$ leakage through the ryanodine receptor from the sarcoplasmic reticulum, giving rise to arrhythmias [87], a common cause of death in ESRD patients.

Shapiro's laboratory has examined whether CKD alone can lead to cardiovascular dysfunction. CKD was induced by partial nephrectomy in rats and mice, and increases in serum concentrations of ouabain and marinobufagenin were observed in CKD animals. This was accompanied with increases in blood pressure, diastolic dysfunction, ventricular hypertrophy and cardiac fibrosis 
as well as evidence of signalling through the NKA-SrcERK signalling cascade $[24,83,88]$. Furthermore, infusion of marinobufagenin resulted in similar biochemical, physiological and morphological changes as observed in animals subjected to partial nephrectomy, whereas active and passive immunisation against marinobufagenin reversed most of these alterations $[24,89]$. In a separate series of studies, the authors examined the effects of marinobufagenin on cardiac fibrosis. Nanomolar concentrations of marinobufagenin (and of other CTS) stimulated the production of collagen in primary cultures of cardiac fibroblasts isolated from mice and rats $[83,88]$. This effect was suggested to be mediated via the NKA-Src-ERK signalling cascade, and collagen synthesis was associated with increased transcription and translation of procollagen [83]. Based on these data it is tempting to conclude that marinobufagenin is solely responsible for the uraemic cardiomyopathy development during CKD. However, it is important to note that the protective effects of immunisation are likely not to be simply mediated by removal of marinobufagenin, as antibodies raised to CTS tend to have poor specificity, as discussed previously. Lack of accurate assays, specific for individual CTS that can detect and quantify nanomolar concentrations of individual CTS, has certainly hindered our progress. Currently, there is a commercially available assay for ouabain but not for measurements of marinobufagenin, telocinobufagin and bufalin. Whether the animal experiments performed thus far have any application to human disease remains to be confirmed. Although the CTS binding site is highly conserved across the evolutionary spectrum [90], rats and mice possess an Asn122His substitution in their NKA $\alpha_{1}$-isoforms, making it less sensitive to CTS [91]. Considering that a large proportion of scientific research is conducted in the rat and mouse, a question of relevance of some of the data to human physiology cannot be disregarded. It should be noted however that $\alpha_{2^{-}}$ and $\alpha_{3}$-isoforms in rats and mice are sensitive to ouabain.

Recent studies suggest that reduction of NKA content (often manifested in heart failure) in conjunction with nanomolar levels of marinobufagenin potentiates marinobufagenin-induced myocyte apoptosis by activation of the caspase 9-regulated pro-apoptotic pathway and contributes to diastolic dysfunction [92]. Interestingly, in a separate study of 140 patients with idiopathic dilated cardiomyopathy, endogenous ouabain was shown to be an independent and incremental marker that predicts the progression of heart failure [93]. Therefore, therapy aimed at antagonising the effects of ouabain or marinobufagenin should reduce the progression of heart failure by pathological remodelling and should reduce arterial hypertension in renal failure patients. The latest advances in our understanding of how CTS contribute to cardiovascular dysfunction during CKD/ESRD represent a fertile environment for the development of novel therapeutics for a human condition that affects a significant proportion of the population.

\section{Overlapping Effects of CTS}

Considering a relatively large number of endogenous CTS that have been identified, the question of biological relevance of this diversity is inevitably posed. The $a_{1^{-}}$ subunit is the dominant subunit in the kidneys and the heart, regulating bulk $\mathrm{Na}^{+}$and therefore presumably involved in long-term adaptive changes to the local milieu. The $\alpha_{2}$-isozyme is considered to have regulatory functions in vasoconstriction $[65,94]$ and cardiac inotropy [95]. It is therefore tempting to assume that each CTS has a particular function, i.e. a tissue-specific NKA receptor. Marinobufagenin was initially reported to demonstrate a high affinity for the NKA, with higher selectivity for the $\alpha_{1}$-subunit [63]. However, Katz et al. [96] and Wang et al. [97] showed that marinobufagenin possesses a very low binding affinity to the NKA, compared to ouabain, and furthermore they showed that marinobufagenin is not selective for either of the 3 NKA isoforms. Digoxin was reported to have a higher affinity for the $\alpha_{2}$-subunit, ouabain a higher affinity for $\alpha_{1}$, whereas marinobufagenin and bufalin cannot discriminate between the isoforms [96]. It is difficult to explain the discrepancies in these studies but it is becoming evident that, rather than marinobufagenin alone mediating specific cardiovascular pathophysiological changes as previously suggested [24, 83], CTS show overlapping specificities for various tasks in the body.

While the functional overlaps are becoming apparent for most CTS, perhaps the most surprising observation is that digoxin was shown to oppose ouabain-induced hypertension in rats $[98,99]$ and possibly even in humans [100]. A study by Song et al. [101] suggests that low doses of digoxin can antagonise the effects of ouabain, possibly explaining the recently reported beneficial effects of low doses of digoxin therapy in heart failure patients [102]. In this context, it is possible that ouabain antagonism represents another beneficial effect of digoxin, on top of already reported effects on improved baroreceptor function and increased vagal tone [103]. The use of digoxin for the treatment of heart failure and possibly even hypertension should therefore be reconsidered; however, toxic effects of higher doses of digoxin, as shown by Rathore et 
al. [104], must not be overlooked. Clearly, if digoxin is to be used more extensively in the clinical setting, closer monitoring of patient serum levels will be required and for this more specific (reduced antibody cross-reactivity) digoxin tests must be developed.

\section{Conclusion}

Our understanding of the role of CTS in cardiovascular physiology and pathophysiology has rapidly increased over the last 20 years. Discovery of marinobufagenin and telocinobufagin have allowed us to scratch the surface and perhaps observe, no more than a glimpse of, a plethora of complex signalling networks that are regulated by this new class of hormones. Ouabain, marinobufagenin and most likely others, as of yet undiscovered CTS, are involved in the regulation of cardiac contraction, vasoconstriction, natriuresis and remodelling of the heart, kidneys and arterial walls. Their secretion seems to be driven by kidney dysfunction or chronic high salt load and is likely to be involved in the pathogenesis of a number of diseases such as uraemic cardiomyopathy, pre-eclampsia, hypertension, congestive heart failure, myocardial ischaemia-induced arrhythmias and diabetes mellitus. Already we have started making use of the limited knowledge accumulated to develop several therapeutic tools for the treatment of hypertension, and some of these are currently undergoing clinical trials. A clear barrier to further expansion of our knowledge is the lack of tools to accurately detect and measure the CTS present in circulation. Furthermore, as our understanding of the structurefunction relationship expands, the development of novel CTS with a greater therapeutic spectrum and better antihypertensive properties will soon become a reality.

\section{Disclosure Statement}

None.

\section{References}

1 Mann JF, Gerstein HC, Pogue J, Bosch J, Yusuf S: Renal insufficiency as a predictor of cardiovascular outcomes and the impact of ramipril: the HOPE randomized trial. Ann Intern Med 2001;134:629-636.

-2 Best PJ, Reddan DN, Berger PB, Szczech LA, McCullough PA, Califf RM: Cardiovascular disease and chronic kidney disease: insights and an update. Am Heart J 2004;148:230-242.

- 3 Tyralla K, Amann K: Cardiovascular changes in renal failure. Blood Purif 2002;20:462-465.

-4 Morth JP, Pedersen BP, Toustrup-Jensen MS, Sorensen TL, Petersen J, Andersen JP, Vilsen B, Nissen P: Crystal structure of the sodiumpotassium pump. Nature 2007;450:10431049.

-5 Shinoda T, Ogawa H, Cornelius F, Toyoshima C: Crystal structure of the sodium-potassium pump at 2.4 A resolution. Nature 2009;459: 446-450.

-6 Ogawa H, Shinoda T, Cornelius F, Toyoshima C: Crystal structure of the sodium-potassium pump $\left(\mathrm{Na}^{+}, \mathrm{K}^{+}\right.$-ATPase $)$with bound potassium and ouabain. Proc Natl Acad Sci USA 2009; 106:13742-13747.

7 Morth JP, Poulsen H, Toustrup-Jensen MS, Schack VR, Egebjerg J, Andersen JP, Vilsen B, Nissen P: The structure of the $\mathrm{Na}^{+}, \mathrm{K}^{+}$-ATPase and mapping of isoform differences and disease-related mutations. Philos Trans R Soc Lond B Biol Sci 2009;364:217-227.

8 Sweadner KJ, Rael E: The FXYD gene family of small ion transport regulators or channels: cDNA sequence, protein signature sequence, and expression. Genomics 2000;68:41-56.
-9 Pavlovic D, Fuller W, Shattock MJ: Novel regulation of cardiac Na pump via phospholemman. J Mol Cell Cardiol 2013;61:83-93.

10 Kaplan JH: Biochemistry of Na,K-ATPase. Annu Rev Biochem 2002;71:511-535.

11 Sweadner KJ: Isozymes of the $\mathrm{Na}^{+}, \mathrm{K}^{+}$ATPase. Biochim Biophys Acta 1989;988: 185-220.

12 Geering K: The functional role of the betasubunit in the maturation and intracellular transport of Na,K-ATPase. FEBS Lett 1991; 285:189-193.

13 Horisberger JD, Jaunin P, Good PJ, Rossier BC, Geering K: Coexpression of alpha 1 with putative beta 3 subunits results in functional $\mathrm{Na}^{+} / \mathrm{K}^{+}$pumps in Xenopus oocytes. Proc Natl Acad Sci USA 1991;88:8397-8400.

14 Crambert G, Hasler U, Beggah AT, Yu C, Modyanov NN, Horisberger JD, Lelievre L, Geering K: Transport and pharmacological properties of nine different human $\mathrm{Na}, \mathrm{K}$ ATPase isozymes. J Biol Chem 2000;275: 1976-1986.

15 Blaustein MP: Sodium ions, calcium ions, blood pressure regulation, and hypertension: a reassessment and a hypothesis. Am J Physiol 1977;232:C165-C173.

16 Bagrov AY, Fedorova OV, Dmitrieva RI, Howald WN, Hunter AP, Kuznetsova EA, Shpen VM: Characterization of a urinary bufadienolide $\mathrm{Na}^{+}, \mathrm{K}^{+}$-ATPase inhibitor in patients after acute myocardial infarction. Hypertension 1998;31:1097-1103.
17 Fedorova LV, Raju V, El-Okdi N, Shidyak A, Kennedy DJ, Vetteth S, Giovannucci DR, Bagrov AY, Fedorova OV, Shapiro JI, Malhotra D: The cardiotonic steroid hormone marinobufagenin induces renal fibrosis: implication of epithelial-to-mesenchymal transition. Am J Physiol Renal Physiol 2009; 296:F922-F934.

18 Fedorova OV, Doris PA, Bagrov AY: Endogenous marinobufagenin-like factor in acute plasma volume expansion. Clin Exp Hypertens 1998;20:581-591.

19 Gallice PM, Kovacic HN, Brunet PJ, Berland YF, Crevat AD: A non-ouabain-like inhibitor of the sodium pump in uremic plasma ultrafiltrates and urine from healthy subjects. Clin Chim Acta 1998;273:149-160.

20 Gonick HC, Ding Y, Vaziri ND, Bagrov AY, Fedorova OV: Simultaneous measurement of marinobufagenin, ouabain, and hypertension-associated protein in various disease states. Clin Exp Hypertens 1998;20:617-627.

21 Hamlyn JM, Blaustein MP, Bova S, DuCharme DW, Harris DW, Mandel F, Mathews WR, Ludens JH: Identification and characterization of a ouabain-like compound from human plasma. Proc Natl Acad Sci USA 1991;88: 6259-6263.

22 Hamlyn JM, Ringel R, Schaeffer J, Levinson PD, Hamilton BP, Kowarski AA, Blaustein MP: A circulating inhibitor of $\left(\mathrm{Na}^{+}+\mathrm{K}^{+}\right)$ ATPase associated with essential hypertension. Nature 1982;300:650-652. 
-23 Harwood S, Mullen AM, McMahon AC, Dawnay A: Plasma OLC is elevated in mild experimental uremia but is not associated with hypertension. Am J Hypertens 2001;14: 1112-1115.

24 Kennedy DJ, Vetteth S, Periyasamy SM, Kanj M, Fedorova L, Khouri S, Kahaleh MB, Xie Z, Malhotra D, Kolodkin NI, Lakatta EG, Fedorova OV, Bagrov AY, Shapiro JI: Central role for the cardiotonic steroid marinobufagenin in the pathogenesis of experimental uremic cardiomyopathy. Hypertension 2006; 47:488-495.

25 Komiyama Y, Dong XH, Nishimura N, Masaki H, Yoshika M, Masuda M, Takahashi H: A novel endogenous digitalis, telocinobufagin, exhibits elevated plasma levels in patients with terminal renal failure. Clin Biochem 2005;38:36-45.

26 Li S, Liu G, Jia J, Miao Y, Gu S, Miao P, Shi X, Wang Y, Yu C: Therapeutic monitoring of serum digoxin for patients with heart failure using a rapid LC-MS/MS method. Clin Biochem 2010;43:307-313.

-27 Manunta P, Stella P, Rivera R, Ciurlino D, Cusi D, Ferrandi M, Hamlyn JM, Bianchi G: Left ventricular mass, stroke volume, and ouabain-like factor in essential hypertension. Hypertension 1999;34:450-456.

28 Periyasamy SM, Chen J, Cooney D, Carter P, Omran E, Tian J, Priyadarshi S, Bagrov A, Fedorova O, Malhotra D, Xie Z, Shapiro JI: Effects of uremic serum on isolated cardiac myocyte calcium cycling and contractile function. Kidney Int 2001;60:2367-2376.

29 Pierdomenico SD, Bucci A, Manunta P, Rivera R, Ferrandi M, Hamlyn JM, Lapenna D, Cuccurullo F, Mezzetti A: Endogenous ouabain and hemodynamic and left ventricular geometric patterns in essential hypertension. Am J Hypertens 2001;14:44-50.

- 30 Gottlieb SS, Rogowski AC, Weinberg M, Krichten CM, Hamilton BP, Hamlyn JM: Elevated concentrations of endogenous ouabain in patients with congestive heart failure. Circulation 1992;86:420-425.

- 31 Stella P, Manunta P, Mallamaci F, Melandri M, Spotti D, Tripepi G, Hamlyn JM, Malatino LS, Bianchi G, Zoccali C: Endogenous ouabain and cardiomyopathy in dialysis patients. J Intern Med 2008;263:274-280.

- 32 Goto A, Ishiguro T, Yamada K, Ishii M, Yoshioka M, Eguchi C, Shimora M, Sugimoto T: Isolation of a urinary digitalis-like factor indistinguishable from digoxin. Biochem Biophys Res Commun 1990;173:1093-1101.

-33 Qazzaz HM, Goudy SL, Valdes R Jr: Deglycosylated products of endogenous digoxin-like immunoreactive factor in mammalian tissue. J Biol Chem 1996;271:8731-8737.

-34 Qazzaz HM, Valdes R Jr: Simultaneous isolation of endogenous digoxin-like immunoreactive factor, ouabain-like factor, and deglycosylated congeners from mammalian tissues. Arch Biochem Biophys 1996;328: 193-200.
35 Sich B, Kirch U, Tepel M, Zidek W, Schoner $\mathrm{W}$ : Pulse pressure correlates in humans with a proscillaridin A immunoreactive compound. Hypertension 1996;27:1073-1078.

- 36 Oda M, Kurosawa M, Numazawa S, Tanaka S, Akizawa T, Ito K, Maeda M, Yoshida T: Determination of bufalin-like immunoreactivity in serum of humans and rats by time-resolved fluoroimmunoassay for using a monoclonal antibody. Life Sci 2001;68:1107-1117.

37 Laredo J, Hamilton BP, Hamlyn JM: Secretion of endogenous ouabain from bovine adrenocortical cells: role of the zona glomerulosa and zona fasciculata. Biochem Biophys Res Commun 1995;212:487-493.

38 Dmitrieva RI, Bagrov AY, Lalli E, SassoneCorsi P, Stocco DM, Doris PA: Mammalian bufadienolide is synthesized from cholesterol in the adrenal cortex by a pathway that is independent of cholesterol side-chain cleavage. Hypertension 2000;36:442-448.

39 Murrell JR, Randall JD, Rosoff J, Zhao JL, Jensen RV, Gullans SR, Haupert GT Jr: Endogenous ouabain: upregulation of steroidogenic genes in hypertensive hypothalamus but not adrenal. Circulation 2005;112:1301-1308.

40 Manunta P, Hamilton BP, Hamlyn JM: Salt intake and depletion increase circulating levels of endogenous ouabain in normal men. Am J Physiol Regul Integr Comp Physiol 2006;290:R553-R559.

41 Shah JR, Laredo J, Hamilton BP, Hamlyn JM: Effects of angiotensin II on sodium potassium pumps, endogenous ouabain, and aldosterone in bovine zona glomerulosa cells. Hypertension 1999;33:373-377.

42 Altamirano J, Li Y, DeSantiago J, Piacentino V 3rd, Houser SR, Bers DM: The inotropic effect of cardioactive glycosides in ventricular myocytes requires $\mathrm{Na}^{+}-\mathrm{Ca}^{2+}$ exchanger function. J Physiol 2006;575:845-854.

43 Goonasekera SA, Molkentin JD: Unraveling the secrets of a double life: contractile versus signaling $\mathrm{Ca}^{2+}$ in a cardiac myocyte. J Mol Cell Cardiol 2012;52:317-322.

-44 Liu J, Tian J, Haas M, Shapiro JI, Askari A, Xie Z: Ouabain interaction with cardiac $\mathrm{Na}^{+} / \mathrm{K}^{+}$ATPase initiates signal cascades independent of changes in intracellular $\mathrm{Na}^{+}$and $\mathrm{Ca}^{2+}$ concentrations. J Biol Chem 2000;275:2783827844.

45 Pierre SV, Xie Z: The Na,K-ATPase receptor complex: its organization and membership. Cell Biochem Biophys 2006;46:303-316.

46 Li Z, Xie Z: The Na/K-ATPase/Src complex and cardiotonic steroid-activated protein kinase cascades. Pflugers Arch 2009;457:635644.

47 Liang M, Tian J, Liu L, Pierre S, Liu J, Shapiro J, Xie ZJ: Identification of a pool of nonpumping Na/K-ATPase. J Biol Chem 2007; 282:10585-10593.

48 Wang H, Haas M, Liang M, Cai T, Tian J, Li $\mathrm{S}$, Xie Z: Ouabain assembles signaling cascades through the caveolar $\mathrm{Na}^{+} / \mathrm{K}^{+}$-ATPase. J Biol Chem 2004;279:17250-17259.
49 Liu J, Liang M, Liu L, Malhotra D, Xie Z, Shapiro JI: Ouabain-induced endocytosis of the plasmalemmal $\mathrm{Na} / \mathrm{K}$-ATPase in LLC-PK1 cells requires caveolin-1. Kidney Int 2005;67: 1844-1854

50 Liu J, Kesiry R, Periyasamy SM, Malhotra D, Xie Z, Shapiro JI: Ouabain induces endocytosis of plasmalemmal $\mathrm{Na} / \mathrm{K}$-ATPase in LLCPK1 cells by a clathrin-dependent mechanism. Kidney Int 2004;66:227-241.

51 Liu J, Periyasamy SM, Gunning W, Fedorova OV, Bagrov AY, Malhotra D, Xie Z, Shapiro JI: Effects of cardiac glycosides on sodium pump expression and function in LLC-PK1 and MDCK cells. Kidney Int 2002;62:21182125.

52 Tian J, Liu J, Garlid KD, Shapiro JI, Xie Z: Involvement of mitogen-activated protein kinases and reactive oxygen species in the inotropic action of ouabain on cardiac myocytes. A potential role for mitochondrial K(ATP) channels. Mol Cell Biochem 2003;242:181187.

53 Bagrov YY, Manusova NB, Egorova IA, Fedorova OV, Bagrov AY: Endogenous digitalis-like ligands and $\mathrm{Na} / \mathrm{K}$-ATPase inhibition in experimental diabetes mellitus. Front Biosci 2005; 10:2257-2262.

54 Peng M, Huang L, Xie Z, Huang WH, Askari A: Partial inhibition of $\mathrm{Na}^{+} / \mathrm{K}^{+}$-ATPase by ouabain induces the $\mathrm{Ca}^{2+}$-dependent expressions of early-response genes in cardiac myocytes. J Biol Chem 1996;271:10372-10378.

55 Dong XH, Komiyama Y, Nishimura N, Masuda M, Takahashi H: Nanomolar level of ouabain increases intracellular calcium to produce nitric oxide in rat aortic endothelial cells. Clin Exp Pharmacol Physiol 2004;31: 276-283.

56 Reuter H, Henderson SA, Han T, Ross RS, Goldhaber JI, Philipson KD: The $\mathrm{Na}^{+}-\mathrm{Ca}^{2+}$ exchanger is essential for the action of cardiac glycosides. Circ Res 2002;90:305-308.

-57 Andrikopoulos P, Baba A, Matsuda T, Djamgoz MB, Yaqoob MM, Eccles SA: $\mathrm{Ca}^{2+}$ influx through reverse mode $\mathrm{Na}^{+} / \mathrm{Ca}^{2+}$ exchange is critical for vascular endothelial growth factor-mediated extracellular signalregulated kinase (ERK) 1/2 activation and angiogenic functions of human endothelial cells. J Biol Chem 2011;286:37919-37931.

58 Gruber KA, Whitaker JM, Buckalew VM Jr: Endogenous digitalis-like substance in plasma of volume-expanded dogs. Nature 1980; 287:743-745.

59 Komiyama Y, Nishimura N, Munakata M, Mori T, Okuda K, Nishino N, Hirose S, Kosaka C, Masuda M, Takahashi H: Identification of endogenous ouabain in culture supernatant of PC12 cells. J Hypertens 2001;19: 229-236.

60 Fedorova OV, Talan MI, Agalakova NI, Lakatta EG, Bagrov AY: Endogenous ligand of alpha(1) sodium pump, marinobufagenin, is a novel mediator of sodium chloride-dependent hypertension. Circulation 2002;105: 1122-1127.
Cardiotonic Steroids and

Cardiomyopathy
Nephron Clin Pract 2014;128:11-21 DOI: $10.1159 / 000363301$ 
61 Bagrov AY, Shapiro JI, Fedorova OV: Endogenous cardiotonic steroids: Physiology, pharmacology, and novel therapeutic targets. Pharmacol Rev 2009;61:9-38.

-62 Fedorova OV, Kolodkin NI, Agalakova NI, Namikas AR, Bzhelyansky A, St-Louis J, Lakatta EG, Bagrov AY: Antibody to marinobufagenin lowers blood pressure in pregnant rats on a high $\mathrm{NaCl}$ intake. J Hypertens 2005; 23:835-842.

63 Fedorova OV, Kolodkin NI, Agalakova NI, Lakatta EG, Bagrov AY: Marinobufagenin, an endogenous alpha-1 sodium pump ligand, in hypertensive Dahl salt-sensitive rats. Hypertension 2001;37:462-466.

-64 Anderson DE, Fedorova OV, Morrell CH, Longo DL, Kashkin VA, Metzler JD, Bagrov AY, Lakatta EG: Endogenous sodium pump inhibitors and age-associated increases in salt sensitivity of blood pressure in normotensives. Am J Physiol Regul Integr Comp Physiol 2008;294:R1248-R1254.

-65 Dostanic-Larson I, Van Huysse JW, Lorenz JN, Lingrel JB: The highly conserved cardiac glycoside binding site of $\mathrm{Na}, \mathrm{K}-\mathrm{ATPase}$ plays a role in blood pressure regulation. Proc Natl Acad Sci USA 2005;102:15845-15850.

-66 Ferrandi M, Molinari I, Barassi P, Minotti E, Bianchi G, Ferrari P: Organ hypertrophic signaling within caveolae membrane subdomains triggered by ouabain and antagonized by PST 2238. J Biol Chem 2004;279:3330633314.

67 Pamnani MB, Chen S, Yuan CM, Haddy FJ: Chronic blood pressure effects of bufalin, a sodium-potassium ATPase inhibitor, in rats. Hypertension 1994;23:I106-I109.

-68 Fedorova OV, Zhuravin IA, Agalakova NI, Yamova LA, Talan MI, Lakatta EG, Bagrov AY: Intrahippocampal microinjection of an exquisitely low dose of ouabain mimics $\mathrm{NaCl}$ loading and stimulates a bufadienolide $\mathrm{Na} / \mathrm{K}$ ATPase inhibitor. J Hypertens 2007;25:18341844.

69 Ferrari P, Ferrandi M, Valentini G, Bianchi G: Rostafuroxin: an ouabain antagonist that corrects renal and vascular $\mathrm{Na}^{+}-\mathrm{K}^{+}$-ATPase alterations in ouabain and adducin-dependent hypertension. Am J Physiol Regul Integr Comp Physiol 2006;290:R529-R535.

-70 Horvat D, Severson J, Uddin MN, Mitchell B, Puschett JB: Resibufagenin prevents the manifestations of preeclampsia in an animal model of the syndrome. Hypertens Pregnancy 2010;29:1-9.

71 Huang BS, Van Vliet BN, Leenen FH: Increases in CSF $\left[\mathrm{Na}^{+}\right]$precede the increases in blood pressure in Dahl S rats and SHR on a high-salt diet. Am J Physiol Heart Circ Physiol 2004; 287:H1160-H1166.

-72 Simchon S, Manger W, Golanov E, Kamen J, Sommer G, Marshall $\mathrm{CH}$ : Handling $22 \mathrm{NaCl}$ by the blood-brain barrier and kidney: its relevance to salt-induced hypertension in Dahl rats. Hypertension 1999;33:517-523.
73 Van Huysse JW, Amin MS, Yang B, Leenen $\mathrm{FH}$ : Salt-induced hypertension in a mouse model of Liddle syndrome is mediated by epithelial sodium channels in the brain. Hypertension 2012;60:691-696.

74 Blaustein MP, Leenen FH, Chen L, Golovina VA, Hamlyn JM, Pallone TL, Van Huysse JW, Zhang J, Wier WG: How $\mathrm{NaCl}$ raises blood pressure: a new paradigm for the pathogenesis of salt-dependent hypertension. Am J Physiol Heart Circ Physiol 2012;302:H1031H1049.

75 Nesher M, Dvela M, Igbokwe VU, Rosen H, Lichtstein D: Physiological roles of endogenous ouabain in normal rats. Am J Physiol Heart Circ Physiol 2009;297:H2026-H2034.

76 Staessen JA, Thijs L, Stolarz-Skrzypek K, Bacchieri A, Barton J, Espositi ED, de Leeuw PW, Dluzniewski M, Glorioso N, Januszewicz A, Manunta P, Milyagin V, Nikitin Y, Soucek M, Lanzani C, Citterio L, Timio M, Tykarski A, Ferrari P, Valentini G, Kawecka-Jaszcz K, Bianchi G: Main results of the ouabain and adducin for specific intervention on sodium in hypertension trial (OASIS-HT): a randomized placebo-controlled phase-2 dose-finding study of rostafuroxin. Trials 2011;12:13.

77 Lopatin DA, Ailamazian EK, Dmitrieva RI, Shpen VM, Fedorova OV, Doris PA, Bagrov AY: Circulating bufadienolide and cardenolide sodium pump inhibitors in preeclampsia. J Hypertens 1999;17:1179-1187.

-78 Adair CD, Buckalew VM, Graves SW, Lam GK, Johnson DD, Saade G, Lewis DF, Robinson C, Danoff TM, Chauhan N, Hopoate-Sitake M, Porter KB, Humphrey RG, Trofatter KF, Amon E, Ward S, Kennedy L, Mason L, Johnston JA: Digoxin immune Fab treatment for severe preeclampsia. Am J Perinatol 2010; 27:655-662.

79 Lam GK, Hopoate-Sitake M, Adair CD, Buckalew VM, Johnson DD, Lewis DF, Robinson CJ, Saade GR, Graves SW: Digoxin antibody fragment, antigen binding (Fab), treatment of preeclampsia in women with endogenous digitalis-like factor: a secondary analysis of the DEEP trial. Am J Obstet Gynecol 2013;209:119 e111-e116.

80 Periyasamy SM, Liu J, Tanta F, Kabak B, Wakefield B, Malhotra D, Kennedy DJ, Nadoor A, Fedorova OV, Gunning W, Xie Z, Bagrov AY, Shapiro JI: Salt loading induces redistribution of the plasmalemmal $\mathrm{Na} / \mathrm{K}$ ATPase in proximal tubule cells. Kidney Int 2005;67:1868-1877.

81 Pullen MA, Brooks DP, Edwards RM: Characterization of the neutralizing activity of digoxin-specific Fab toward ouabain-like steroids. J Pharmacol Exp Ther 2004;310:319325.

82 Mulvany MJ: Small artery remodelling in hypertension. Basic Clin Pharmacol Toxicol 2012;110:49-55.
83 Kennedy DJ, Elkareh J, Shidyak A, Shapiro AP, Smaili S, Mutgi K, Gupta S, Tian J, Morgan E, Khouri S, Cooper CJ, Periyasamy SM, Xie Z, Malhotra D, Fedorova OV, Bagrov AY, Shapiro JI: Partial nephrectomy as a model for uremic cardiomyopathy in the mouse. Am J Physiol Renal Physiol 2008;294:F450-F454.

84 Bignami E, Casamassima N, Frati E, Lanzani C, Corno L, Alfieri O, Gottlieb S, Simonini M, Shah KB, Mizzi A, Messaggio E, Zangrillo A, Ferrandi M, Ferrari P, Bianchi G, Hamlyn JM, Manunta P: Preoperative endogenous ouabain predicts acute kidney injury in cardiac surgery patients. Crit Care Med 2013;41:744755.

85 Tian J, Haller S, Periyasamy S, Brewster P, Zhang H, Adlakha S, Fedorova OV, Xie ZJ, Bagrov AY, Shapiro JI, Cooper CJ: Renal ischemia regulates marinobufagenin release in humans. Hypertension 2010;56:914-919.

86 Barry WH, Hasin Y, Smith TW: Sodium pump inhibition, enhanced calcium influx via sodium-calcium exchange, and positive inotropic response in cultured heart cells. Circ Res 1985;56:231-241.

87 Scoote M, Williams AJ: The cardiac ryanodine receptor (calcium release channel): emerging role in heart failure and arrhythmia pathogenesis. Cardiovasc Res 2002;56:359-372.

88 Elkareh J, Kennedy DJ, Yashaswi B, Vetteth S, Shidyak A, Kim EG, Smaili S, Periyasamy SM, Hariri IM, Fedorova L, Liu J, Wu L, Kahaleh MB, Xie Z, Malhotra D, Fedorova OV, Kashkin VA, Bagrov AY, Shapiro JI: Marinobufagenin stimulates fibroblast collagen production and causes fibrosis in experimental uremic cardiomyopathy. Hypertension 2007;49: 215-224.

89 Haller ST, Drummond CA, Yan Y, Liu J, Tian J, Malhotra D, Shapiro JI: Passive immunization against marinobufagenin attenuates renal fibrosis and improves renal function in experimental renal disease. Am J Hypertens 2014;27:603-609.

90 Lingrel JB: The physiological significance of the cardiotonic steroid/ouabain-binding site of the Na,K-ATPase. Annu Rev Physiol 2010; 72:395-412.

91 Price EM, Lingrel JB: Structure-function relationships in the Na,K-ATPase alpha subunit: site-directed mutagenesis of glutamine-111 to arginine and asparagine- 122 to aspartic acid generates a ouabain-resistant enzyme. Biochemistry 1988;27:8400-8408.

-92 Liu C, Bai Y, Chen Y, Wang Y, Sottejeau Y, Liu L, Li X, Lingrel JB, Malhotra D, Cooper CJ, Shapiro JI, Xie ZJ, Tian J: Reduction of $\mathrm{Na} / \mathrm{K}$ ATPase potentiates marinobufagenin-induced cardiac dysfunction and myocyte apoptosis. J Biol Chem 2012;287:16390-16398.

93 Pitzalis MV, Hamlyn JM, Messaggio E, Iacoviello $\mathrm{M}$, Forleo $\mathrm{C}$, Romito $\mathrm{R}$, de Tommasi $\mathrm{E}$, Rizzon P, Bianchi G, Manunta P: Independent and incremental prognostic value of endogenous ouabain in idiopathic dilated cardiomyopathy. Eur J Heart Failure 2006;8: 179-186. 
94 Blaustein MP, Zhang J, Chen L, Hamilton BP: How does salt retention raise blood pressure? Am J Physiol Regul Integr Comp Physiol 2006;290:R514-R523.

95 Despa S, Lingrel JB, Bers DM: $\mathrm{Na}^{+} / \mathrm{K}^{+}$ATPase alpha2-isoform preferentially modulates $\mathrm{Ca}^{2+}$ transients and sarcoplasmic reticulum $\mathrm{Ca}^{2+}$ release in cardiac myocytes. Cardiovasc Res 2012;95:480-486.

96 Katz A, Lifshitz Y, Bab-Dinitz E, Kapri-Pardes E, Goldshleger R, Tal DM, Karlish SJ: Selectivity of digitalis glycosides for isoforms of human Na,K-ATPase. J Biol Chem 2010;285: 19582-19592.

-97 Wang J, Velotta JB, McDonough AA, Farley RA: All human $\mathrm{Na}^{+}-\mathrm{K}^{+}$-ATPase alpha-subunit isoforms have a similar affinity for cardiac glycosides. Am J Physiol Cell Physiol 2001;281:C1336-C1343.
98 Manunta P, Hamilton J, Rogowski AC, Hamilton BP, Hamlyn JM: Chronic hypertension induced by ouabain but not digoxin in the rat: antihypertensive effect of digoxin and digitoxin. Hypertens Res 2000; 23(suppl):S77-S85.

-99 Kimura K, Manunta P, Hamilton BP, Hamlyn JM: Different effects of in vivo ouabain and digoxin on renal artery function and blood pressure in the rat. Hypertens Res 2000;23(suppl):S67-S76.

100 Abarquez RF Jr: Digitalis in the treatment of hypertension. A preliminary report. Acta Med Phil 1967;3:161-170.

101 Song H, Karashima E, Hamlyn JM, Blaustein MP: Ouabain-digoxin antagonism in rat arteries and neurones. J Physiol 2014; 592:941-969.
02 Ahmed A, Rich MW, Love TE, Lloyd-Jones DM, Aban IB, Colucci WS, Adams KF, Gheorghiade M: Digoxin and reduction in mortality and hospitalization in heart failure: a comprehensive post hoc analysis of the DIG trial. Eur Heart J 2006;27:178-186.

103 Gheorghiade M, Adams KF Jr, Colucci WS: Digoxin in the management of cardiovascular disorders. Circulation 2004;109:29592964.

104 Rathore SS, Curtis JP, Wang Y, Bristow MR, Krumholz HM: Association of serum digoxin concentration and outcomes in patients with heart failure. JAMA 2003;289:871-878.

105 Schoner W, Scheiner-Bobis G: Role of endogenous cardiotonic steroids in sodium homeostasis. Nephrol Dial Transplant 2008; 23:2723-2729. 